\title{
Compliance to Positive Health, Dignity and Prevention Services among HIV Infected Index Partners in HIV Sero-Discordant Relationships in Nairobi County, Kenya

\author{
Akolo $\mathbf{M}^{\mathbf{1}, 2,5 *}$, Gichuki $\mathbf{R}^{3}$, Chitwa $\mathbf{M}^{2}$, Kimani $\mathbf{J}^{2,4,5,6}$ and Osero $\mathbf{J}^{1}$
}

${ }^{1}$ School of Public Health-Kenyatta University, Kenya

${ }^{2}$ Partners in Health and Development in Africa, Kenya

${ }^{3}$ AMREF Health-Kenya, P.O BOX 27691-00506, Nairobi, Kenya

${ }^{4}$ Medical Microbiology, University of Manitoba 745 Bannatyne Avenue Winnipeg, Manitoba R3E OW2, Canada

${ }^{5}$ Canadian Africa Prevention Trials Network-East Africa HUB, Kenya

${ }^{6}$ University of Nairobi Institute of Tropical and Infectious Diseases, Nairobi University, P.O Box 19676-00202, Nairobi

\begin{abstract}
Introduction: This study evaluated compliance to Positive Health, Dignity and Prevention [PHDP] practice among index partners in HIV sero-discordant relationships in Nairobi County, Kenya. PHDP involves a set of interventions that helps people living with HIV lead a complete and healthy life besides reducing risk of HIV transmission. These interventions were adopted in Kenya in 2013 by the National AIDS and STI Control Program [NASCOP], Ministry of Health and the United States Government [USG] funded affiliates. The evaluation focused on demographic factors, knowledge, perception and challenges encountered while adopting PHDP practices among index client.
\end{abstract}

Methods: A cross sectional descriptive study design was used, 370 index partners in sero discordant relationship were recruited from three clinics within Nairobi County. The clinic's patient registry was used to contact sequentially those who met the inclusion criteria. Standardized data collecting tools were administered. Data was cleaned and analyzed using SPSS VER 22.0.

Results: Out of 370 respondents $19.7 \%$ were male. $40.1 \%$ had education level of primary school and below. The group exhibited high PHDP knowledge at $90.8 \%$ however, only $66.5 \%$ complied with PHDP practice. There was significant relationship between condom supply, condom demonstration and PHDP compliance at $\mathrm{P}$ values of 0.034 and 0.018 respectively. Odds ratio showed those index partners who had no challenge in accessing condom demonstration and supply complied more to PHDP practice. Consistence condom use was at $53.4 \%$, while $28.2 \%$ had multiple sex partners.

Conclusion: PHDP compliance is low which calls for improvement. There is significance relationship between condom supply/demonstration and PHDP compliance.

Keywords: Compliance; Transmission; Counselling; Perception; Condom; Health; HIV

\section{Introduction}

Positive health, dignity, and prevention [PHDP] is evidence based intervention that helps people living with Human Immunodeficiency Virus [HIV] live a fulfilling and healthy life and reduce the risk of transmission of the virus to others especially those in HIV serodiscordant relationships. PHDP is characterized by its systematic delivery of a range of combination, behavioral and socio-cultural services within clinical and community settings [1]. The following interventions constitute PHDP package in clinical setting; Condom demonstration and supply, risk-reduction counseling, assessment of partner status, provision/referral of partner testing, assessment for sexually transmitted infections [STIs], assessment of family planning needs and assessment of adherence to care and treatment [2]. A client has to access at least a minimum package during the last visit made to the comprehensive care center in order to have complied with PHDP, and this entails adherence to care and treatment plus any other three interventions outlined above.

Globally, 34 million people currently live with Human Immunodeficiency virus [HIV], 69\% reside in Sub Saharan Africa [SSA] [3] Kenya has an estimated adult HIV prevalence rate of $5.2 \%$ representing 1.6 million individuals infected with HIV, 44\% of these infections were due to heterosexual sex within a union or regular partnership. Sixty one percent of all HIV infected married or cohabiting couples in Kenya are considered to be discordant, this corresponds to about 260,000 couples nationwide [4] slightly below the national prevalence rate.

Since the early 80 s until recently, our understanding of HIV prevention as it relates to people living with HIV and in sero-discordance relationship has been inconsistent or ill-defined. In addition, policies and programs aimed at people living with HIV were designed, for the most part, without the meaningful involvement of people living with HIV [1]. PHDP the relatively new area of focus for HIV prevention programs was created to address this gap. Historically, HIV prevention efforts focused on reducing HIV risk among individuals assumed to be HIV-negative. Program planners were hesitant to target PLHIV with HIV prevention interventions due to concerns about victim-

*Corresponding author: Akolo M, School of Public Health, Kenyatta University, P.O Box 43844, Nairobi, Canadian Africa Prevention Trials Network-East Africa HUB, Kenya, Tel: +254721677442; E-mail: Makolo@phdaf.org

Received May 20, 2016; Accepted June 29, 2016; Published July 06, 2016

Citation: Akolo M, Gichuki R, Chitwa M, Kimani J, Osero J (2016) Compliance to Positive Health, Dignity and Prevention Services among HIV Infected Index Partners in HIV Sero-Discordant Relationships in Nairobi County, Kenya. J AIDS Clin Res 7: 597. doi:10.4172/2155-6113.1000597

Copyright: ( 2016 Akolo M, et al. This is an open-access article distributed unde the terms of the Creative Commons Attribution License, which permits unrestricted use, distribution, and reproduction in any medium, provided the original author and source are credited. 
blaming and increasing stigma for PLHIV. However, wider access and availability of antiretroviral therapy and associated care has been scaled-up dramatically worldwide creating an environment where HIV infected individuals can be targeted with prevention programs. In addition, efforts to mainstream both HIV care and combating stigma have also been scaled up as prevention strategies under PHDP [1,5].

Positive Health Dignity and Prevention argues that if you improve and maintain the dignity of the person living with HIV or support the individual living with HIV around their broad health needs, this will result in a range of benefits including a reduction in the likelihood of new infections. In 2011, after consultations with PLHIV GNP+ and UNAIDS released Positive Health, Dignity and Prevention [PHDP] document, a policy framework that promotes the rights, health and empowerment of PLHIV to take leadership roles in HIV prevention responses while creating a more conducive environment for HIV prevention efforts [1]. America, Botswana, South Africa Nigeria, Uganda and Kenya are a few of the countries that have implanted PHDP into their care and treatment of HIV/AIDS package. Within this study we aim to look at the knowledge, challenges and perceptions of PHDP among index clients in HIV sero-discordant relationship and how each affects PHDP compliance by calculating PHDP minimum package uptake.

\section{Methods}

\section{Study setting and population}

The participants in this study were HIV positive index partners in HIV sero-discordant relationships actively enrolled at the Positive health, dignity and prevention program at the Pumwani, Baba dogo and Majengo Comprehensive Care Clinics situated in Nairobi County.

\section{Study design and sampling}

The study was a descriptive cross-sectional study that took six months. The study population was purposively selected. The three study sites were selected through simple random sampling from Comprehensive Care Center registries at the National AIDS and STI Control Program. Systematic sampling was used to select study participants from the clinic registries after calculating the Kth, while purposive sampling was used to identify those who participated in focus group discussions. Approval was granted from the graduate school and ethical clearance by Kenyatta University Ethical review Committee and permit from NACOSTI was also obtained. All eligible participants; aged 18 years and above index partners in active HIV sero-discordant relationships without any mental disability and willing to participate in the study signed an informed consent. Permission to conduct the study at the three different clinics' was obtained from the facility management boards.

\section{Variables, definitions and statistical analysis}

The independent variables were knowledge, perceptions, challenges and demographic factors while the dependent variable was compliance to PHDP practices. One on one paper questionnaire was administered by trained research assistants to capture the socio-demographic data, level of knowledge, challenges, perception and current practice of PHDP practice among index partners in HIV sero-discordance relationship. A focused group discussion guide was used to gather qualitative data from three groups each constituted 10 participants. Quantitative data analysis was done using SPSS version 22.0. The alpha level was set at 0.05 . Qualitative content analysis was used to analyze open ended variables. Thematic analysis was used to summarize the information generated from the focus group discussions. Chi square was used to test association between categorical values.

\section{Results}

\section{Socio-demographic factors}

A total of 370 participants were enrolled into the study. Three focus group discussions were also conducted to determine the perception of PHDP practices among index partners in sero-discordant relationships. Eighty point three percent of the study participants were female. Fifty seven percent of the study participants were married of which $52.4 \%$ of them were living with their sex partners. Twenty two percent of the total respondents claimed to be single, $2.7 \%$ divorced, $11.6 \%$ separated, $6.2 \%$ widowed but all had a HIV negative sex partner that had qualified them to be in the sero-discordant cohorts. Forty six point five percent had secondary education, $39.5 \%$ of the total study participants earned a monthly salary above Ksh 10001 (Table 1).

\section{Knowledge of PHDP indicators among index partners in sero-discordant relationships}

PHDP knowledge analysis showed that one person [0.3\%] claimed to have never heard of HIV despite being HIV positive, on care and treatment for at least 3 months, while $99.7 \%$ had heard of HIV. Ninety nine percent knew the importance of HIV disclosure to sex partner and $99.2 \%$ had knowledge on condom use. Twenty eight point two percent did not know that presence of STI increases the chance of acquiring HIV, while $77.2 \%$ could relate presence of STI to increased chance of acquiring HIV. Ninety point eight percent knew that alcohol consumption interferes with HIV care and treatment. At least above $90 \%$ of the study participants had knowledge on all the PHDP indicators.

Out of 370 respondents $76.5 \%$ learnt about HIV infection from the hospital setting, 98.5\% knew that HIV can be transmitted through sex, while only $41.3 \%$ named HIV as one of the STIs. The study participants had good knowledge on contraceptive methods however 3.5\% did not know any type of contraceptive methods. The focus group discussion showed that there was adequate knowledge among the respondents on the importance of each of the PHDP interventions. These included the importance of discordant couple support groups adherence, importance of condom use and family planning. One respondent said pertaining

\begin{tabular}{|c|c|c|c|}
\hline Characteristic & & $\mathbf{N}$ & $\%$ \\
\hline s & & & \\
\hline$(n=370)$ & Male & 73 & 19.7 \\
\hline Living with & Female & 297 & 80.3 \\
\hline partner & No & 176 & 47.6 \\
\hline (n=370) & & 194 & \\
\hline Education & None & 10 & 52.4 \\
\hline level $(n=370)$ & Primary & 141 & 38.1 \\
\hline & Secondary & 172 & 46.5 \\
\hline & Tertiary & 47 & 12.7 \\
\hline Source of & Employed & 116 & 31.4 \\
\hline income & Business & 190 & 51.4 \\
\hline$(n=370)$ & Other & 58 & 15.7 \\
\hline & None & 6 & 1.6 \\
\hline Salary $(n=370)$ & $0-5000$ & 138 & 37.3 \\
\hline & $5001-10000$ & 86 & 23.2 \\
\hline & 10001 and above & 146 & 39.5 \\
\hline
\end{tabular}

Table 1: Social-demographic data of index partners. 
family planning that if one gives birth frequently without using family planning for spacing the body immunity will be compromised, exposing her to opportunistic infection. The data also demonstrated a significant inverse relationship between knowledge on contraceptive use and compliance to PHDP practice with $\mathrm{p}$ value of 0.017 . This shows that the respondents without contraceptive knowledge complied more to PHDP practice than those with contraceptive knowledge (Table 2).

\section{Perceptions of PHDP practice among index partners}

Out of 370 respondents, $28.1 \%$ perceived HIV status disclosure a problem and they cited abandonment, stigma and violence as reasons hindering disclosure, $3.8 \%$ did not perceive condom use as a method of HIV prevention. Seventy seven point two percent of the respondents understood that STI increases the risk of HIV transmission. Most of the respondents perceived partner testing as very important. On alcohol consumption $62.9 \%$ said that alcohol consumption might make one forget to take their treatment completely or on scheduled time leading to ART resistance and poor immunity. There was no significant relationship between study participants perceptions and compliance to PHDP practices. In FGD most of the study participants had a positive perception of positive health, dignity and prevention interventions. Interventions reported by the respondents included proper use of condoms, STI testing, ARV adherence, regular visits to the health facility, couple HIV testing and counseling and HIV testing for the discordant partner. One of the reasons cited was that regular visits to the health facility helped the HIV discordant partner learn how to use condoms properly.

\section{PHDP Challenges among index partners}

Data collected on challenges on PHDP service included issues around affordability, availability, appropriateness and acceptance. Ninety percent found it affordable to honor their care and treatment clinic appointments; but $10 \%$ had a challenge in honoring their appointments due to long distance, lack of bus fare or lack of time off from work or other commitments. Above $97 \%$ found all PHDP services acceptable to HIV positive individuals. Ninety one point nine percent reported to have used PHDP services while all study participants found PHDP practice important. The focus group discussions showed that male partner influence was crucial in the adoption of some of the PHDP interventions including condom use and family planning. One respondent reported that male partners may have a problem with contraceptive uptake because of the perception that it affects libido. In addition condom use may be affected by cultural norms that give men more power and a lack of understanding on the importance of condoms. One respondent reported that men do not use condoms as they find them uncomfortable. Distance between the partners was noted to influence the relationship status of a discordant couple by increasing the risk of multiple partner relationships or casual sex. This was noted to influence both men and women.

Out of 370 respondents $66.5 \%$ complied with PHDP practice while $33.5 \%$ did not. Bivariate analysis of challenges showed that there was a significant relationship between condom demonstration and PHDP compliance with $\mathrm{P}$ value of 0.018 . There is also a significant relationship between condom supply and compliance to PHDP practice with $\mathrm{P}$ value of 0.034 .

The odd ratio of 2.42 indicates that those who attended a condom demonstration session complied with PHDP practice two times more than those that did not. Also, the odds ratio of 5.06 indicates that those respondents who accessed condom supply complied with PHDP practice five times more than those who did not (Table 3 ).

\section{Index partners PHDP practice}

Out of the 370 respondents $14.6 \%$ did not use condom on their last sexual act with their regular partners. Twenty eight point two percent had other sexual partners and [88] 86.3\% of them did not know the other partners' HIV status, [75] 73.5\% of those with other sex partners had disclosed their HIV status after intimacy.

Out of 370 respondents $27.3 \%$ took alcohol of which $91.2 \%$ reported having had sex while drunk. Forty one percent respondents had not been screened for STI in the last 6 months, while $4.9 \%$ of those screened had tested positive and accessed treatment. Only $66.5 \%$ of the participants had accessed adherence counseling and other three PHDP services meeting the minimum package hence, complied with PHDP practice as outlined in Table 4 .

\section{Discussion}

There are many index women who are HIV positive compared to men at $80.3 \%$. This agrees with results presented by CDC [6] that stated male to female HIV penile-vaginal transmission appears to be more efficient than female to male transmission, this shows the importance of reaching out to HIV positive individuals especially men to disclose their HIV status as early as possible to their sex partners and/or get them tested. However, despite female index partners being more than the males in our sample, bivariate analysis shows that males complied more with the PHDP interventions compared to females. Literacy levels were slightly average in this study group, $59.1 \%$ had attained secondary or tertiary level of education. This differs with results presented by Ruzangira [7] who showed above $70 \%$ of the index partners in their

\begin{tabular}{|c|c|c|c|c|c|c|}
\hline \multirow[b]{2}{*}{ Characteristics } & \multicolumn{2}{|c|}{ Compliance } & \multirow[b]{2}{*}{ P-Value } & \multirow[b]{2}{*}{$\begin{array}{l}\text { Odds Ratio } \\
\text { (OR) }\end{array}$} & \multicolumn{2}{|c|}{$95 \% \mathrm{Cl}$ for OR } \\
\hline & \multirow[t]{2}{*}{ No } & \multirow[t]{2}{*}{ Yes } & & & Lower & Upper \\
\hline \multicolumn{5}{|l|}{ Contraceptive } & & \\
\hline \multicolumn{7}{|l|}{ knowledge } \\
\hline No (Ref) & $1(6.3 \%)$ & $15(93.8 \%)$ & 0.017 & 1 & & \\
\hline Yes & $124(35.0 \%)$ & $230(65.0 \%)$ & & 0.12 & 0.02 & 0.95 \\
\hline \multicolumn{7}{|l|}{ Condom use demo } \\
\hline No (Ref) & $16(53.3 \%)$ & $14(46.7 \%)$ & 0.018 & 1 & & \\
\hline Yes & $109(32.1 \%)$ & $231(67.9 \%)$ & & 2.42 & 1.14 & 5.14 \\
\hline \multicolumn{7}{|l|}{ Condom supplied } \\
\hline No (Ref) & $5(71.4 \%)$ & $2(28.6 \%)$ & 0.034 & 1 & & \\
\hline Yes & $120(33.1 \%)$ & $243(66.9 \%)$ & & 5.06 & 0.97 & 26.48 \\
\hline
\end{tabular}

Table 2: Bivariate analysis of PHDP compliance. 


\begin{tabular}{|c|c|c|}
\hline Practices & $\mathbf{n}$ & $\%$ \\
\hline \multicolumn{3}{|c|}{ Do you desire more children $(n=368)$} \\
\hline No & & 49.2 \\
\hline Yes & & 45.7 \\
\hline Not sure & & 5.2 \\
\hline \multicolumn{3}{|l|}{ Do you use FP (n=297) } \\
\hline No & & 16.2 \\
\hline Yes & & 83.8 \\
\hline \multicolumn{3}{|l|}{ Did you Use condom last } \\
\hline \multicolumn{3}{|l|}{$\operatorname{sex}(n=370)$} \\
\hline No & & 14.6 \\
\hline Yes & & 85.4 \\
\hline \multicolumn{3}{|c|}{ Was it your regular sex partner } \\
\hline \multicolumn{3}{|l|}{$(n=370)$} \\
\hline No & & 28.9 \\
\hline Yes & & 71.1 \\
\hline \multicolumn{3}{|c|}{ How often do you use condom used } \\
\hline \multicolumn{3}{|c|}{ with regular partner $(n=328)$} \\
\hline Always & & 53.4 \\
\hline Sometimes & & 43 \\
\hline Never & & 3.7 \\
\hline \multicolumn{3}{|l|}{ N/A } \\
\hline \multicolumn{3}{|c|}{ Do you have other sexual partner } \\
\hline \multicolumn{3}{|l|}{$(n=366)$} \\
\hline No & 262 & 71.8 \\
\hline Yes & 104 & 28.2 \\
\hline \multicolumn{3}{|c|}{ Do you know your casual partners } \\
\hline \multicolumn{3}{|l|}{ HIV status ( $n=102)$} \\
\hline No & 88 & 86.3 \\
\hline Yes & 14 & 13.7 \\
\hline \multicolumn{3}{|c|}{ Time disclosed HIV status to casual sex } \\
\hline \multicolumn{3}{|l|}{ partners $(n=102)$} \\
\hline Immediately & 11 & 10.8 \\
\hline After intimacy & 75 & 73.5 \\
\hline Never & 16 & 15.7 \\
\hline \multicolumn{3}{|c|}{ Do you take alcohol ( $n=366)$} \\
\hline No & 266 & 72.7 \\
\hline Yes & 100 & 27.3 \\
\hline \multicolumn{3}{|c|}{ Frequency of taking alcohol $(n=100)$} \\
\hline Every day & 4 & 4 \\
\hline 2-6 times a week & 73 & 73 \\
\hline Once a week & 13 & 13 \\
\hline Other & 10 & 10 \\
\hline Had sex when drunk ( $n=1$ & & \\
\hline No & 7 & 6.9 \\
\hline Yes & & 91.2 \\
\hline Can't remember & & 1.9 \\
\hline Honor last appointment $(\mathrm{n}$ & & \\
\hline No & & 7.6 \\
\hline Yes & & 92.4 \\
\hline Screened STI last 6 months & & \\
\hline No & & 41 \\
\hline Yes & & 57.9 \\
\hline Can't remember & & 1.1 \\
\hline Ever had STD past 6 months & & \\
\hline No & & 94 \\
\hline Yes & & 4.9 \\
\hline Can't remember & & 1.1 \\
\hline Access treatment $(n=1$ & & \\
\hline Private hospital & & 27.8 \\
\hline Government hospital & & 66.7 \\
\hline Other & & 5.6 \\
\hline
\end{tabular}

Table 3: PHDP Practice among index partners. sample had only primary school education. This study showed that $57 \%$ of the couples were married to their sex partners while $43 \%$ cohabited with HIV negative partners and were sexually active, this could increase the rate of HIV incidence as outlined in Kenyan AIDS survey report [4] that high rate of HIV transmission occurs between HIV sero discordant couples who are in unstable relationships.

Above $90 \%$ of the study participants exhibited knowledge of all PHDP indicators whereas only $66.5 \%$ complied with PHDP practice. These findings are similar to those generated by a study done by De Walque that clearly demonstrated a high HIV incidence among HIV negative partners in HIV discordant relationship even when the couple was aware of their HIV discordant state [8]. Respondents without contraceptive knowledge complied to PHDP intervention slightly more than those with the knowledge at an odds ratio of 0.12 . Only $16.2 \%$ of the study participants were not on any family planning method, this shows good uptake of family planning among discordant couples. This finding also agrees with findings in Kenya Health Demographic Survey that states the practice of family planning in Kenya has increased steadily since the early 1980s [9]. The focus group discussion showed that there was adequate knowledge among the respondents on the importance of each of the PHDP interventions.

Participants' perception of PHDP practice was positive overall. Most of the study participants stated that STI increases the risk of one acquiring HIV, this is also supported by two different studies done by Clellan that states the presence of STI is an important correlates of HIV-1 transmission within discordant heterosexual relationships [10]. Seventy two percent perceived disclosure of one's status as necessary and doable, some participants found it impossible to disclose their HIV status to their sex partners and expressed fear of abandonment, stigma and violence as a hindrance to disclosure. This is supported by study done by UNAIDS in 2012 that states most new HIV infection occur in HIV sero-discordant couples where disclosure remains low. This is also outlined in HIV sero discordant couples study results that was done by Bernard, [11] it showed sero-discordant couples desire intimate contacts and children born to them despite one of the partners being HIV sero-positive and this led to fear of disclosure citing abandonment or violence by the HIV positive partner.

On alcohol consumption focus group discussion respondents said that alcohol consumption interferes with ones thinking hence may contribute to engaging in unprotected sex and forgetting to swallow their medicine. This is supported by findings from a study done by National Institute of Alcohol Abuse and Alcoholism [12] that indicates alcohol consumption affects one's judgment hence diming perception risk of behavior that may lead to HIV transmission.

Most of the study participants found PHDP intervention; affordable, available, appropriate and acceptable and very important for their well-being. Bivariate analysis of PHDP accessibility, affordability and availability challenges showed that there was significance relationship between accessing condom demonstration and PHDP compliance as well as significant relationship between condom supply and compliance to PHDP. The odds ratio showed that the respondents who accessed both condom demonstration and supply complied more to PHDP practices compared to those who did not access either supply or condom demonstration. This agrees with results from a study done by Stephen et al. that shows the importance of consistence condom use and HIV infection among discordant couples [13]. Focus group discussions showed that male partners have a big influence on the adoption of most of the PHDP interventions including condom use and family planning. Condom use was seen as a result of unfaithfulness from the partner 
Page 5 of 5

\begin{tabular}{|c|c|c|c|}
\hline PHDP services offered & & & \\
\hline & Scores & Frequency (f) & Percentage (\%) \\
\hline Adherence Only & 0 & 3 & $0.7 \%$ \\
\hline Adherence with one service & 1 & 42 & $11.4 \%$ \\
\hline Adherence with two services & 2 & 56 & $15.1 \%$ \\
\hline Adherence with three services & 3 & 246 & $66.5 \%$ \\
\hline Three services only without adherence & 4 & 14 & $3.8 \%$ \\
\hline Four services only without adherence & 5 & 8 & $2.2 \%$ \\
\hline Five services only without adherence & 6 & 1 & $0.3 \%$ \\
\hline
\end{tabular}

Table 4: PHDP compliance among index clients.

requesting its use, this finding corroborates with results from three different studies [14-16] which showed that male gender was reported to control the decision to use condom in sero-discordant relationship. Multiple Partnerships were also cited as a challenge affecting adoption of PHDP interventions, $28 \%$ of the respondents had other sexual partners of which $86.3 \%$ did not know the other partners HIV status, this agrees with results from a study done by Mac Kenzie that showed concurrent relationships contribute to spread of HIV [17] . Distance between the partners was also noted to influence the relationship status of a discordant couple by increasing the risk of multiple partner relationships or casual sex resulting into acquiring HIV, this is supported by a study done by [18] that stated the direction of the spread of HIV was not only from returning.

\section{Conclusion}

The index clients have high knowledge of PHDP services and there is significance relationship between importance of using contraceptive in HIV positive and PHDP compliance. There is no significant relationship between perceptions of PHDP practice and compliance to PHDP practice by the index partners; however stigma, violence and fear of abandonment were reported to hinder disclosure. There is significant relationship between challenges in condom supply, condom demonstration and compliance to PHDP practice. The respondents who had no challenge tend to comply more to PHDP than those with a challenge.

\section{Acknowledgement}

We would like to acknowledge all the study participants, the management staff of the three clinics and Canadian African Prevention Trials Network for funding the work.

\section{References}

1. GNP+ (2009) Positive health, dignity and prevention. J Acquir Immune Deficiency Syndrome 37: S122-S125.

2. Remien RH, Berkman A, Myer L, Bastos FI, Kagee A, et al. (2008) Integrating HIV care and HIV prevention: Legal, policy and programmatic recommendations. AIDS 22 Suppl 2: S57-65.

3. UNAIDS (2013) Positive health, dignity and prevention: Operational guidelines Geneva and Amsterdam.

4. Kenya Ministry of Health (2013) Kenya AIDS indicator survey 2012. Nairobi, Kenya.
5. UNAIDS (2009) Joint United Nations Program on HIVIAIDS report on the globa AIDS epidemic, Geneva.

6. CDC (2012) Family planning methods and practice, Africa, Centers for Disease Control and Prevention, Washington, DC.

7. Ruzagira E, Wandiembe S, Abaasa A, Bwanika AN, Bahemuka U, et al. (2011) HIV incidence and risk factors for acquisition in HIV discordant couples in Masaka, Uganda: An HIV vaccine preparedness study. PLoS One 6: e24037.

8. De Walque (2006) Discordant couples: HIV infection among couples in Burkina Faso, Cameroon, Ghana, Kenya and Tanzania. World Bank: Washington, DC.

9. Kenya Ministry of Health (2009) Kenya demographic health survey, Nairobi, Kenya.

10. McClelland RS, Sangare L, Hassan WM, Lavreys L, Mandaliya K, et al. (2007) Infection with Trichomonas vaginalis increases the risk of HIV-1 acquisition. J Infect Dis 195: 698-702.

11. Bernard EJ (2009) Positive health, dignity and prevention. Technical Consultation Report 27-28 April 2009, Hammamet, Tunisia.

12. National Institute on Alcohol Abuse and Alcoholism (2002) Alcohol alert No 57

13. Stephenson R, Baschieri A, Clements S, Hennink M, Madise N (2007) Contextual influences on modern contraceptive use in sub-Saharan Africa. Am J Public Health 97: 1233-1240.

14. Sarkar NN (2008) Barriers to condom use. Eur J Contracept Reprod Health Care 13: 114-122.

15. Ngure K, Mugo N, Celum C, Baeten JM, Morris M, et al. (2012) A qualitative study of barriers to consistent condom use among HIV-1 serodiscordant couples in Kenya. AIDS Care 24: 509-516.

16. Eaton A, van Der Straten A (2009) Concurrent sexual partnerships among individuals in HIV sero-discordant heterosexual couples. Int J STD AIDS 20: 679-682.

17. Mackenzie C, Kiragu K (2007) Should voluntary counseling and testing counselors address alcohol use with clients? Finding from an operation research study in Kenya, Horizon research update. Nairobi; Population council.

18. Lurie MN, Williams BG, Zuma K, Mkaya-Mwamburi D, Garnett GP, et al. (2003) Who infects whom? HIV-1 concordance and discordance among migrant and non-migrant couples in South Africa. AIDS 17: 2245-2252. 